\title{
25 years after the accident at the Chernobyl nuclear power plant: Radioecological lessons
}

\author{
R.M. Alexakhin and S.A. Geras'kin \\ Russian Institute of Agricultural Radiology \& Agroecology, Obninsk, Kaluga region, Russia
}

\begin{abstract}
The area affected by the Chernobyl accident has become a unique test site where long-term ecological and biological consequences of a drastic change in a range of environmental factors as well as trends and intensity of selection are studied in natural settings. The consequences of the Chernobyl accident for biota varied from an enhanced rate of mutagenesis to damage at the ecosystem level. The severity of radiation effects was strongly dependent on the dose received in the early period after the accident. The most exposed phytocenoses and soil animals' communities exhibited dose dependent alterations in the species composition and reduction in biological diversity. These findings make a valuable contribution to scientific and public understanding of the environmental risks of ionizing radiation and to debates on the environmental costs, benefits and risks of nuclear energy.
\end{abstract}

\section{INTRODUCTION}

Although it has been 25 years since the Chernobyl accident, controversy and uncertainty still exist relative to environmental consequences of this, the most severe radiation accident in the humans' history. The Chernobyl accident has no analogs in both area of radioactive contamination and absorbed doses to biota species. The large-scale and nonuniform radioactive contamination of the area affected as well as variety of biota responses at different levels of biological organization have made investigations of radioecological consequences of the Chernobyl accident a source of actually unique information. In the affected region extensive observations were carried out of the migration of biologically mobile radionuclides (primarily ${ }^{137} \mathrm{Cs},{ }^{90} \mathrm{Sr},{ }^{239} \mathrm{Pu}$, etc.) in various natural environments. The effects of different parameters on radionuclide transfer via the trophic chains were assessed in natural conditions.

\section{RADIONUCLIDES MIGRATION IN THE ENVIRONMENT}

The radiation accident at the Chernobyl NPP in 1986, classified as the largest anthropogenic catastrophe, has caused radioactive contamination of huge territories (over $150000 \mathrm{~km}^{2}$ with the ${ }^{137} \mathrm{Cs}$ contamination level above $37 \mathrm{kBq} / \mathrm{m}^{2}$ ). Soil is the main depot of radionuclides in terrestrial biogeocenoses. A characteristic feature of ${ }^{137} \mathrm{Cs}$ behavior in the soil is its gradual "ageing" (weathering) which manifests itself as a reduced chemical mobility and bioavailability. With time the amount of exchangeable ${ }^{137} \mathrm{Cs}$ in soil decreases and its plant uptake drops 3-5 times, with the rate of decrease for the root uptake being eventually slower. As a result, 20 years after the accident this process occurs very slowly.

A most important segment of the natural environment influencing the overall dose received by humans is the agricultural production [1]. Since the early days after the contamination a largescale program of protective and rehabilitative measures has been launched in the affected region. Its main goals were to reduce the radionuclide migratory fluxes in the environment, primarily those leading to humans; to restrict inclusion of radioactive substances to the biological chains; and, ultimately, to reduce the exposure dose to the population and improve the sanitary-ecological situation. These countermeasures concerned all the affected natural environments - agricultural sphere, forest ecosystems, herbaceous biocenoses, hydrobiocenoses, etc. 
Based on the economic, ecologic and social importance, of all the natural environments, the top priorities in the implementation of countermeasures were given to the sphere of agricultural production. The regulation of dose burdens to the population using agricultural countermeasures appeared to be the major reserve for the radioecological improvement of the situation.

The reasons for classification of the Chernobyl accident as a rural one are as follows: 1) radionuclides containing agricultural foodstuffs produced in the accidental region were one of the leading, and in some cases, dominating sources of irradiation of the population; 2) the main population in the accidental region was rural ("rural" type of diet); 3) other things being equal, the exposure dose to the rural residents was higher than to the urban population; 4) agricultural production was the major segment of the national economy in the affected region.

The system of protective measures in the agriculture was introduced in the affected region in an area of more than 700000 ha with the population of some 3 million people and about 6000 settlements. These areas saw different highly effective countermeasures in various branches of agricultural production, including special schemes of organic and mineral fertilizing, and amelioration (2-3 fold reduction in the radionuclide content in foodstuffs), special techniques of soil cultivation (1.5 times), radical improvement of meadow-pasture lands (3-8 times), special system of animal feeding and the use of selective fodder additives ( 8 fold), cultivation of farm crops with minimal accumulation of radionuclides (5-10 fold), special procedures of primary raw food reprocessing (5 times and more).

Forests occupy about $30 \%$ of the contaminated territory, with the forested area where ${ }^{137} \mathrm{Cs}$ levels are above $37 \mathrm{kBq} / \mathrm{m}^{2}$ being some $40000 \mathrm{~km}^{2}$. The contribution of forest products (mushrooms, berries) to ${ }^{137} \mathrm{Cs}$ human uptake varies between 12 and $50 \%$ of the total transfer. For the representatives of wild flora and fauna typical is a very slow reduction in ${ }^{137} \mathrm{Cs}$ concentration with time compared to the dynamics of these processes for the agricultural plants. Thus, 20 years after the accident, ${ }^{137} \mathrm{Cs}$ concentration in mushrooms and forest berries remains unchanged compared to the first years after the accident. In the same conditions ${ }^{137} \mathrm{Cs}$ concentration in the main types of farm products (plant and animal production) dropped 10 times or more (role of countermeasures and ${ }^{137} \mathrm{Cs}$ "biogeochemical ageing").

The aquatic environment in the affected area included the cooling pond, one of the most contaminated water bodies, the river systems and lakes. The estimated dynamics of ${ }^{137} \mathrm{Cs}$ concentration in fish during 20-25 years after the accident shows very small changes (ignoring the decay). About 8 million people received additional irradiation due to the consumption of drinking water from the Dnieper cascade, another 32 million people received additional dose burdens from the consumption of fish and use of contaminated water for irrigation.

The radioecological investigations in the Chernobyl affected region on simultaneous studying the irradiation impacts on man and a wide range of biota representatives [2] helped to verify the correctness of the ICRP paradigm for radiation protection of the environment. According to this paradigm, if man is adequately protected by radiological protection standards then biota is also adequately protected (with rare exception). The validity of this postulate was confirmed during the studies in the agricultural sphere in the Chernobyl zone. The irradiation of man and biota was compared as well as the consequences of the exposure at various densities of radionuclide $\left({ }^{90} \mathrm{Sr}\right.$ and $\left.{ }^{137} \mathrm{Cs}\right)$ contamination, and in this case the total effect from external and internal (i.e. from incorporated radionuclides) exposure was considered. Simultaneously, ${ }^{90} \mathrm{Sr}$ and ${ }^{137} \mathrm{Cs}$ levels in the soil were estimated which comply with the radiation standards on the radionuclide concentrations in food products (human diet). It has been found that in the event when the environment is contaminated with ${ }^{90} \mathrm{Sr}$ and ${ }^{137} \mathrm{Cs}$ and their concentrations are within the standards (i.e. man is protected), then biota (soil mesofauna, high plants and animals) also prove to be protected. This, therefore, substantiates the correctness of the ICRP paradigm [3].

\section{EFFECTS ON NON-HUMAN SPECIES}

In general, there are three distinct time periods in which very different radiological conditions were dominated. The maximum biota exposure fell within the first 10-20 days after the accident when the 
major contributors to the absorbed doses were short-lived radionuclides. The second phase extended through the summer and autumn of 1986 when the exposure dose rate dropped to $20-25 \%$ of the initial value due to decay of the short-lived isotopes as well as migration of the radionuclides into the soil. The last phase of chronic radiation exposure with low dose rate was started from the beginning of the 1987 and is continue up to now. The major contributors to the absorbed doses in this period are long-lived radionuclides, mainly ${ }^{137} \mathrm{Cs}$.

The first post-accident year was most critical in terms of dose formation to plants and animals as well as manifestation of biological effects. It is important, that the Chernobyl accident has occurred in late April, the period of accelerated growth and formation of the reproductive organs, when plant communities and many mesofauna species were the most radiosensitive. The most prominent effect is related with radiation damage to conifers. High retention capacities of stand canopy with respect to radioactive fallout resulted in high doses absorbed by meristems of trees. $\beta$-radiation being the main contributor to the absorbed by plants and animals doses in 1986. Mass mortality of pine trees in the area of 600 ha represent a striking example of radiation damage at the ecosystem level, and provide convincing proof of enhanced sensitivity of forest ecosystems to radiation exposure. The number of invertebrates in the litter layer within the $10-\mathrm{km}$ zone was reduced by a factor of 30 and reproduction was strongly impacted [4]. This effect has not been predicted from pre-Chernobyl data. Pronounced effects on small rodents, including mortality (number of rodents decreased by a factor of 2-10 within the 10-km zone) was also has been registered [5].

In the radiation affected ecosystems two groups of effects are identified [5]. Irradiation of plants and animals with lethal and sublethal doses (primary effects) results in the disruption of ecological relations between the components of ecosystems and in further (secondary) disturbances. The disturbances of ecological interrelations are induced by the following factors: (1) changes in microclimatic and edaphic conditions (in affected coniferous forests, because of improvement of both light and mineral nutrition condition, more radioresistant deciduous species actively develop); (2) disturbances in the synchronism of seasonal phases in the development of ecologically connected groups of organisms (shifts in the time of leaves blossoming and eggs of leaf worms hatching); (3) imbalance in food interrelations between consumers and producers (decrease in food resources as a result of irradiation); (4) changes in biological pressure as a result of species differences in radioresistance (changes towards prevalence of more radioresistant species in meadow phytocenoses; disturbances in both host-parasites and predator-pray relationships); (5) induced by ionizing radiation changes in affected communities make open ecological niches for immigration of new species.

Radiation effects in natural and agricultural ecosystems are dependent on the radiosensitivity of dominant species. Coniferous trees should be mentioned (Fig. 1, [6]) among the most radiosensitive plant species, mammals are the most radiosensitive representatives of animal species while coniferous forests are the most sensitive communities at the ecosystem level.

Radiation levels in the $30-\mathrm{km}$ zone are still much higher than those considered safe for human habitation. Because of their particular use of the habitat, plants and animals inhabited affected by ChNPP accident areas may receive doses of radiation exposure that substantially greater than those of humans occupying the same area [2]. Nevertheless wildlife appears to have been relatively unaffected by the radiation and has therefore benefited from the absence of human disturbance and damage through agriculture, forestry, hunting, fishing and so on. It has resulted in a considerable growth in the populations of wild animals in the 30-km ChNPP zone. By the spring of 1988 the population of wild boars in the $30-\mathrm{km}$ ChNPP zone was 8 times in excess that of the pre-accidental level, the populations of elk, deer, stork, wolf, fox and mouse-like rodents increased manifold [7]. Similar trends are characteristic for other species. To date, the Chernobyl exclusion zone has become a breeding area for white-tailed eagle, spotted eagle, eagle owl, crane and black stork. In this respect, the most severe nuclear power plant accident in the history had positive ecological consequences.

On the other hand, physiologic degradation and loss of immunity in plants and animals in the affected area has activated a nidus of infectious diseases such as tularemia, encephalitis and fungal pathogens. 


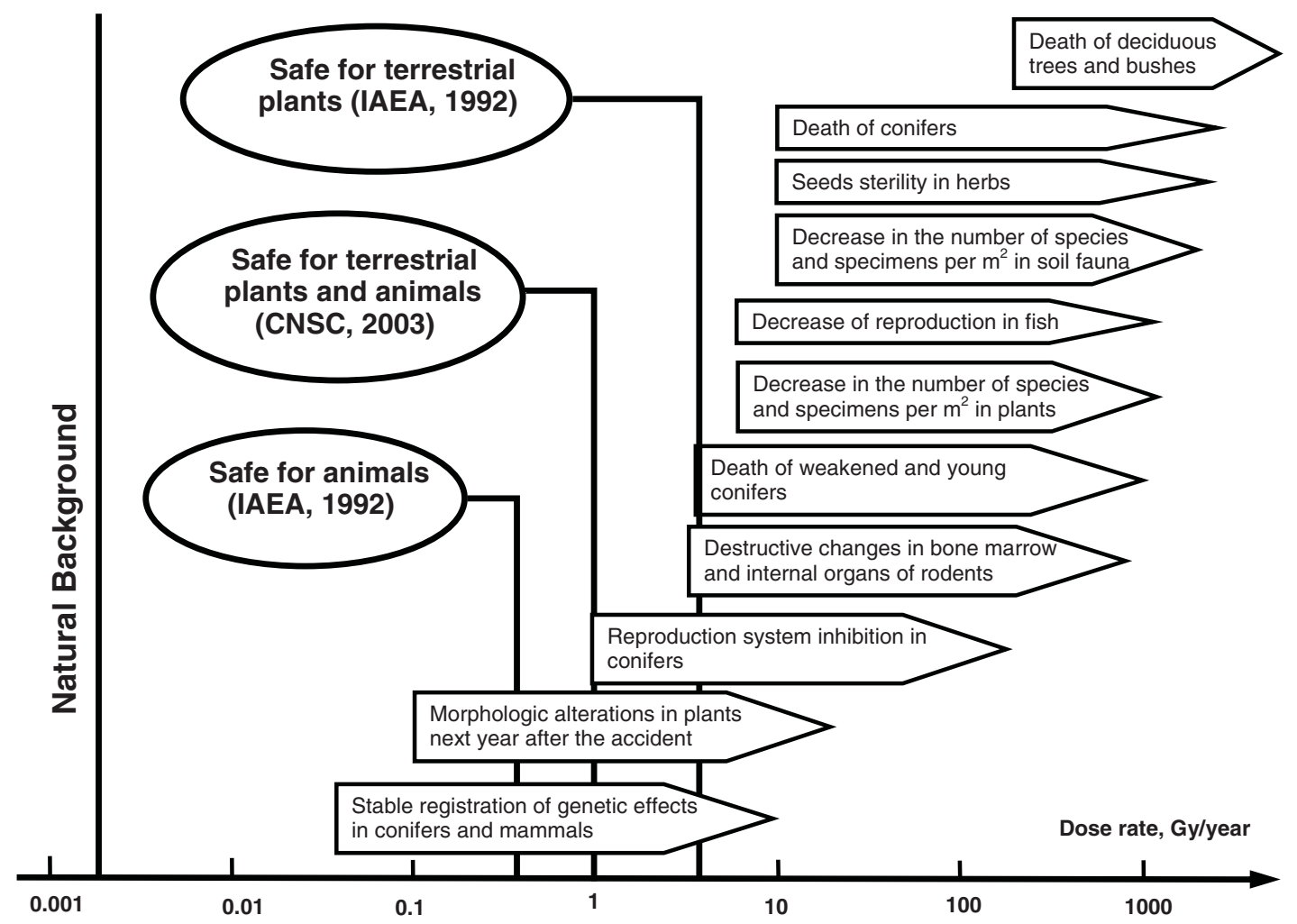

Figure 1. A comparison of effects observed on non-human species in the conditions of the 30-km Chernobyl Exclusion Zone [6] with estimated no effect values recommended by International Atomic Energy Agency and Canadian Nuclear Safety Commission.

Forest and fruit trees in the 30-km ChNPP zone were seriously injured by pests [8]. Within this zone accelerated development of new phytopathogenic forms, races with enhanced virulence, accelerated horizontal transfer of genes among different species of microorganisms became possible [9]. These pathogens could be easily exported out of the contaminated areas. Therefore, the 30-km ChNPP zone may be an environmental hazard and the ecological processes within the zone need to be monitored.

The removal of human residents complicates any examination of population-level effects to wild life at the 30-km ChNPP zone. Nevertheless, there are well-known facts of adaptation to radiation of plant and animal populations to the changed conditions of the 30-km ChNPP zone [10-13]. Moreover, an opinion exists [14] that under conditions of the 30-km ChNPP zone the selection plays in favor of the least specialized primeval genotypes. Overall, the above data suggest that adaptation to chronic radiation exposure is a complex long-time process which includes interconnected changes at different levels of biological organization.

Far less evident are the genetic consequences for biota inhabiting areas with enhanced level of radioactive contamination. Levels of contamination and dose rate estimates reported $[15,16]$ would be expected to confer considerable insult to genetic material by ionizing radiation. Whether the observed levels of genetic anomalies in plants and animals inhabiting areas affected by Chernobyl accident have any detrimental biological significance to populations is still not known [17]. A study of the population-genetic consequences of the Chernobyl accident is directly connected with the assessment of the adaptive capacities of biota and comparison of these with the pace of environmental changes. The experience of ecological research points to the increase of the phenotypical variability in natural 
populations under technogenous influence of which the genetic nature as well as dynamics within generations remain poorly known. Mutations with slightly negative fitness effects could be easily exported out of the contaminated areas via organisms' migration, with consequences for the populations that have not been directly exposed to radiation from the accident. Although these studies are well documented, the role of microevolutionary processes in natural populations' response to low-level chronic exposure is still not clearly understood. Further long-term observations are required in order to understand exactly the dynamics of a mutation load to natural populations inhabiting areas with enhanced levels of radioactive contamination. Much has yet to be learned before we will be able to give an objective and comprehensive assessment of the genetic consequences of the Chernobyl catastrophe for natural plant and animal populations.

\section{CONCLUSIONS}

Finally, large-scale radioecological studies performed in the areas affected by the largest nuclear power plant accident in the history have made it possible to obtain unique information on responses of living nature at different levels of biological organization, from molecular-cellular to ecosystem, in conditions of wide-ranging and extremely heterogeneous radioactive contamination of wide areas. These findings make a valuable contribution to scientific and public understanding of the environmental risks of ionizing radiation and to debates on the environmental costs, benefits and risks of nuclear energy. Within the 30-km Chernobyl NPP zone, where humans are absent, unique ecosystems are developing, where representatives of numerous taxonomic groups of biota are reproducing against the background of drastic changes in the range of ecological factors. The investigations in this area raise a number of key questions regarding the long-term effects of anthropogenic pollution on natural populations; their findings widen our knowledge of the nature of adaptation processes. The $30-\mathrm{km}$ ChNPP zone has become a unique test site, where in natural conditions long-term ecological and biological consequences are studied of a dramatic change in the complex of environmental factors, trends and intensity of selection.

\section{Acknowledgments}

This work was partly supported by Russian Foundation for Basic Research (grants 11-04-00670 and 11-04-97524).

\section{References}

[1] Alexakhin R.M. Radioprotection 44 (2009) 821-824.

[2] Fesenko S.V., Alexakhin R.M., Geras'kin S.A., et al. J Environ Radioact 80 (2005) 1-25.

[3] Alexakhin R.M. Pochvovedenie 12 (2009) 1487-14-89. (in Russian)

[4] Krivolutsky D., Pokarzhevsky A. Sci Total Environ 112 (1992) 69-77.

[5] Alexakhin R.M., Buldakov L.A., Gubanov V.A., et al. Large radiation accidents: consequences and protective countermeasures. Moscow: IzdAT Publisher; 2004.

[6] Geras'kin S.A., Fesenko S.V., Alexakhin R.M. Environment International 34 (2008) 880-897.

[7] Sokolov V.E., Ryabov I.N., Ryabtsev I.A., et al. Sov Sci Rev F Physiol Gen Biol 8 (1994)1-124.

[8] Krivolutsky D.A. Rus. J. Ecology 31 (2000) 257-262.

[9] Dmitriev A., Krizanovskaya M., Guscha N., Grodzinsky D. In: Proceedings of the $35^{\text {th }}$ annual meeting of the European Radiation Research Society. Kiev, Ukraine; 2007. p. 109-117.

[10] Kovalchuk I., Abramov V., Pogribny I., Kovalchuk O. Plant Physiology 135 (2004) 357-363.

[11] Fedotov I.S., Kal'chenko V.A., Igonina E.V., Rubanovich A.V. Radiation Biology. Radioecology 46 (2006) 283-288. (in Russian)

[12] Glazko T.T., Grodzinsky D.M., Glazko V.I. Radiation Biology. Radioecology 46 (2006) 488-493. (in Russian) 
[13] Tsytsugina V.G., Polikarpov G.G. Radiation biology. Radioecology 46 (2006) 200-207. (in Russian)

[14] Glazko V.I. Animal Science Papers and Reports 19 (2001) 95-109.

[15] Chesser R.K., Sugg D.W., Lomakin M.D., et al. Environ. Toxicol. Chem 19 (2000) 305-312.

[16] Ryabokon N.I., Smolich I.I., Kudryashov V.P., Goncharova R.I. Radiat. Environ. Biophys 44 (2005) 169-181.

[17] Geras'kin S.A., Oudalova A.A., Dikareva N.S. et al. Ecotoxicology (2011) DOI 10.1007/s10646011-0664-7 